\title{
Comparison of energy performance between passenger cars and motorcycles in Taiwan by decomposition analysis
}

\author{
I. J. Lu ${ }^{1}$, S. J. $\operatorname{Lin}^{1} \&$ C. Lewis ${ }^{2}$ \\ ${ }^{I}$ Department of Environmental Engineering, National Cheng Kung \\ University, Taiwan, Republic of China \\ ${ }^{2}$ Department of Resources Engineering, National Cheng Kung University, \\ Taiwan, Republic of China
}

\begin{abstract}
Transportation can facilitate the mobility of people and goods over space and time, but it also accelerates energy consumption, and it may cause serious environmental pollution. Based on relevant energy and emission databases, passenger cars and motorcycles are major sources of energy consumption and pollutant emissions in Taiwan. This paper aims to identify the direct and intricate characteristics affecting the energy consumption and performance of passenger cars and motorcycles in Taiwan. Decomposition analysis was used to quantify the relative contributions from energy intensity, the vehicle kilometers per unit car, vehicular structure share, vehicle expansion and economic productivity from 1990 to 2004. The results indicated that the number of passenger cars and motorcycles increased by $138.2 \%$ and $62.7 \%$ over the 14 years. Also, the increases of aggregate fuel consumption were 4.1 million kiloliters and 1.4 million kiloliters, respectively. Furthermore, the results of decomposition analysis indicated that the economic development and energy intensity were two key factors for the rise of vehicle's fuel consumption, while vehicle intensity had a significant positive contribution to energy conservation. Compared with the increased effect on motorcycles' fuel demand, the ratio of vehicle kilometers per unit car to passenger car was improved because the growth rate of vehicle-km was lower than the number of passenger cars. The share of passenger cars in road transportation increased from $24.6 \%$ to $32.7 \%$ while it declined in motorcycles from $68.4 \%$ to $61.3 \%$, which means the "vehicular structure share" factor had a negative effect on passenger cars' fuel demand and an improvement in motorcycle energy consumption. To improve the energy intensity, the strategies include proper fuel/car taxation, and enhancing high occupancy vehicle measures by regulation and economic incentives. Also, increased use of the mass rapid transit system (MRT) and combining road-rail networks would improve efficiency.
\end{abstract}

Keywords: decomposition analysis, economic growth, energy consumption, motorcycle, passenger car. 


\section{Introduction}

A transportation system is fundamental to national progress, economic activity, industrial development and living standard. With the rapid growth of economy and industrial development in Taiwan during the past several decades, the demand of transportation has also increased rapidly. Road transportation is not only the major north-south thoroughfare but also the primary transport mode for most of the people. In order to facilitate the economic activities and to ease the mobility of people and goods over space and time, several projects such as the Sun Yat-sen Expressway, Second Freeway, West Coast Highway and East-West Highway, etc. were constructed in succession. The construction of an integrated road transportation network could accelerate energy consumption and result in serious environmental pollution, even though it can boost regional development, economic activities and the mobility of the people. According to the statistics [1], the number of motor vehicles in Taiwan grew by $80.8 \%$ from 1990-2004, with an increase of transport-related energy consumption by $87.1 \%$. By the end of 2004, the energy consumption of the transportation sector reached 14.4 million kiloliters, accounting for $22.7 \%$ of total final energy consumption in Taiwan [2]. This suggests that Taiwan is challenged by a high demand of energy consumption from rapid economic development. Recognizing sustainable development as a priority course in the $21^{\text {st }}$ century, the government of Taiwan held a second national energy conference in 2005. The energy performance of major sectors for the past several years was examined in the second national energy conference in order to upgrade energy efficiency and to plan national energy policy for reducing the indirect impacts of the post-Kyoto Protocol period. In this study, the comparisons between passenger car and motorcycle are made by the relevant energy and emission database for the share of private vehicles over 90\%. Furthermore, we used the Divisia index approach to explore the relative contributions of different factors to the increase of traffic fuel consumption for getting a more comprehensive understanding of the interrelationships of vehicle growth, economic productivity and energy consumption, and providing a helpful reference for planning the national transport policy in Taiwan.

Decomposition indices, such as Laspeyres and Divisia, are widely-used approaches to explore the relative contribution of different factors affecting the variation of energy use, energy intensity and atmospheric pollution emission. Ang and Lee [3] compared five specific methods and found that the adaptive weighting and the simple average Divisia index approach tended to yield smaller residuals in decomposition. The influences of pollution coefficient, fuel mix, energy intensity, economic growth and industrial structure to the increase of emission changes for the major economic sectors in Taiwan were explored by Lin and Chang [4]. They found that economic growth was the key factor for the increase of $\mathrm{CO}_{2}, \mathrm{NO}_{\mathrm{x}}$ and $\mathrm{SO}_{2}$ during 1980-1992, while the influence of fuel mix was limited. Ang and Pandiyan [5] decomposed energy-related $\mathrm{CO}_{2}$ emission in the manufacturing industry by Divisia index approach and found that the intensity effect had a great impact on the aggregate $\mathrm{CO}_{2}$ emission changes in 
China, Taiwan and South Korea. The variation of $\mathrm{CO}_{2}$ emission from the transportation sector in Italy was decomposed by Mazzarino [6], who found that the growth of GDP was the main factor for the increase of $\mathrm{CO}_{2}$. Lee and Lin [7] employed input-output structure decomposition analysis to identify the relative contribution of each factor that affected $\mathrm{CO}_{2}$ emission changes of Taiwan's petrochemical industries during 1984-1994. Ang [80] compared the properties of decomposition analysis and concluded that the multiplicative and additive logarithmic mean Divisia index approach (LMDI) is the best method from a theoretical standpoint, ease of operation and result interpretation. Pollution coefficient, energy intensity, structural changes and economic activity were adopted by Paula et al. [9] to explore the effects for the increase of $\mathrm{CO}_{2}$ emission in India from 1980 to 1996. Ang [10] proposed a practical guide for the logarithmic mean Divisia index (LMDI) method and used industrial energy consumption and $\mathrm{CO}_{2}$ emissions as examples for realizing the applications and advantages of the LMDI approach. The simple average Divisia index approach with a rolling base year was adopted by Lin et al. [11] to identify the characteristics of $\mathrm{CO}_{2}$ emission changes from industrial sectors in Taiwan.

The objective of this study is to examine the historical performances (19902004) of energy consumption and environmental emissions from passenger cars and motorcycles in Taiwan. Also, the impacts for the changes in energy intensity, the vehicle kilometers per unit car, vehicular structure share, vehicle expansion and ratio of economic productivity to the increase of transport energy consumption were examined with the aid of decomposition analysis in order to improve future transportation strategies.

\section{Methodology}

Decomposition analysis has been applied in many fields to assess an industry's direct and intricate characteristics affecting its changes in energy consumption or pollutant emission. In general, these methods decompose an object of interest into a multiplication of several components to identify the relative influence of each factor according to its variation. The simple average Divisia index method is adopted in this study for the reasons of simplicity and small residuals. Since this decomposition approach allows us to decompose energy consumption in a multiplicative form, the fuel consumption of passenger cars and motorcycles can be expressed as:

$$
E_{i t}=\frac{E_{i t}}{V K T_{i t}} \times \frac{V K T_{i t}}{N_{i t}} \times \frac{N_{i t}}{N_{t}} \times \frac{N_{t}}{G_{t}} \times G_{t}
$$

$\mathrm{E}_{\mathrm{it}}$ : quantity of energy consumption by ith vehicle in year $\mathrm{t}$ (million kiloliter), $\mathrm{VKT}_{\mathrm{it}}$ : length of the vehicle kilometers of travel by ith vehicle in year $\mathrm{t}$ (vehicle kilometer),

$\mathrm{N}_{\mathrm{it}}$ : number of ith vehicle in year $\mathrm{t}$ (unit vehicles),

$\mathrm{N}_{\mathrm{t}}$ : number of aggregate motor vehicles in year $\mathrm{t}$ (unit vehicles),

$\mathrm{G}_{\mathrm{t}}$ : gross domestic product in year $\mathrm{t}$ (billion 2000 US dollars),

Equation (1) can be simplified in the following form: 
where

$$
\mathrm{E}_{\mathrm{it}}=\mathrm{I}_{\mathrm{it}} \times \mathrm{K}_{\mathrm{it}} \times \mathrm{S}_{\mathrm{it}} \times \mathrm{V}_{\mathrm{t}} \times \mathrm{G}_{\mathrm{t}}
$$

$\mathrm{I}_{\mathrm{it}}=\mathrm{E}_{\mathrm{it}} / \mathrm{VKT}_{\mathrm{it}}$ : energy intensity of ith vehicle in year $\mathrm{t}$,

$\mathrm{K}_{\mathrm{it}}=\mathrm{VKT}_{\mathrm{it}} / \mathrm{N}_{\mathrm{it}}$ : vehicle kilometers per unit vehicle in year $\mathrm{t}$,

$\mathrm{S}_{\mathrm{it}}=\mathrm{N}_{\mathrm{it}} / \mathrm{N}_{\mathrm{t}}$ : structure share of ith vehicle in year $\mathrm{t}$,

$\mathrm{V}_{\mathrm{t}}=\mathrm{N}_{\mathrm{t}} / \mathrm{G}_{\mathrm{t}}$ : motor vehicle growth per unit GDP in year $\mathrm{t}$,

Equation (2) can be further expressed as the decomposition of energy demand growth rate into the sum of the growth rates for each component. That is, differentiating both sides of equation (2) with respect to time $t$ gives:

$$
\frac{d E_{i t}}{d t}=\frac{d I_{i t}}{I_{i t}} \times \frac{E_{i t}}{d t}+\frac{d K_{i t}}{K_{i t}} \times \frac{E_{i t}}{d t}+\frac{d S_{i t}}{S_{i t}} \times \frac{E_{i t}}{d t}+\frac{d V_{t}}{V_{t}} \times \frac{E_{i t}}{d t}+\frac{d G_{t}}{G_{t}} \times \frac{E_{i t}}{d t}
$$

By integrating both sides of equation (3) from year 0 to year t yields:

$$
\Delta E_{i t}=\int_{0}^{t} d \ln \left(I_{i t}\right) \times E_{i t}+\int_{0}^{t} d \ln \left(K_{i t}\right) \times E_{i t}+\int_{0}^{t} d \ln \left(S_{i t}\right) \times E_{i t}+\int_{0}^{t} d \ln \left(V_{t}\right) \times E_{i t}+\int_{0}^{t} d \ln \left(G_{t}\right) \times E_{i t}
$$

From the concept of the simple average parametric Divisia method, the integral of equation (4) can be measured by the mean of the beginning-points and endpoints over a short period of time because the data in this study is discrete.

$$
\begin{gathered}
\Delta E_{i t}=\ln \left(\frac{I_{i t}}{I_{i o}}\right) \times\left(\frac{E_{i t}+E_{i o}}{2}\right)+\ln \left(\frac{K_{i t}}{K_{i o}}\right) \times\left(\frac{E_{i t}+E_{i o}}{2}\right)+\ln \left(\frac{S_{i t}}{S_{i o}}\right) \times\left(\frac{E_{i t}+E_{i o}}{2}\right)+\ln \left(\frac{\mathrm{V}_{\mathrm{t}}}{V_{0}}\right) \times\left(\frac{\mathrm{E}_{i t}+\mathrm{E}_{\mathrm{i} 0}}{2}\right) \\
+\ln \left(\frac{G_{t}}{G_{o}}\right) \times\left(\frac{E_{i t}+E_{i o}}{2}\right)+R D=D I+D K+D S+D V+D G+R D
\end{gathered}
$$

DI, DK, DV, DS, DV and DG in equation (5) represent the Divisia indices for the contributions due to changes in energy intensity, vehicle kilometers per unit vehicle, vehicular structure share, vehicle intensity and economic productivity; $\mathrm{RD}$ is the residual term.

\section{Data}

The gross domestic product is adopted from the OECD statistics database (19902004), whereas the number of motor vehicles in Taiwan is from the report "Statistical Abstract of Transportation and Communications" [2]. The estimate of vehicle's fuel consumption is based on the multiplication of the total number of vehicles and the total vehicle kilometers of travel, which is divided by the average fuel efficiency ( $\mathrm{km} /$ kiloliter). Furthermore, the adjustment of a motor vehicle's energy requirement is made according to the proportion of the vehicle's energy consumption and the aggregate energy demand of the road transportation sector in Taiwan [1].

\section{Results}

\subsection{Number of motor vehicles in Taiwan}

As a developing country, the gross domestic product in Taiwan experienced an increased growth rate of $5.30 \%$ per year from 1990 to 2004 . This effect is also reflected in the growth of motor vehicles. According to the statistics, the number 
of motor vehicles in Taiwan increased from 9.2 million vehicles in 1990 to 16.6 million vehicles in 2004 , with the annual growth rate of $4.32 \%$. Table 1 shows the structure share of motor vehicles in Taiwan during 1990-2004. It reveals that passenger cars and motorcycles are the major transport modes in Taiwan, which accounted for more than $93 \%$ of vehicles, followed by light trucks $(4.6 \%)$, heavy trucks $(1.1 \%)$ and buses $(0.5 \%)$. Despite motorcycles having the advantage of mobility and being inexpensive in comparison to passenger cars, the number of motorcycles increased by 3.9 million vehicles over the 14 - year period, with the proportion of motorcycles decreasing from $68.4 \%$ to $61.3 \%$. On the other hand, the number of passenger cars in road transportation grew at a rate of $6.39 \%$ per year, with a structure share of $24.6 \%$ in 1990 compared to $32.7 \%$ in 2004 .

Table 1: $\quad$ Structure share of motor vehicles in Taiwan.

\begin{tabular}{|c|c|c|c|c|c|}
\hline Year & Bus & Heavy Truck & Light Truck & Passenger Car & Motorcycle \\
\hline 1990 & $0.47 \%$ & $1.29 \%$ & $5.22 \%$ & $24.62 \%$ & $68.39 \%$ \\
\hline 1991 & $0.39 \%$ & $1.08 \%$ & $4.68 \%$ & $22.99 \%$ & $70.86 \%$ \\
\hline 1992 & $0.39 \%$ & $1.12 \%$ & $4.64 \%$ & $23.96 \%$ & $69.89 \%$ \\
\hline 1993 & $0.40 \%$ & $1.11 \%$ & $4.43 \%$ & $24.62 \%$ & $69.44 \%$ \\
\hline 1994 & $0.41 \%$ & $1.07 \%$ & $4.21 \%$ & $25.14 \%$ & $69.17 \%$ \\
\hline 1995 & $0.51 \%$ & $1.29 \%$ & $4.86 \%$ & $31.81 \%$ & $61.54 \%$ \\
\hline 1996 & $0.50 \%$ & $1.18 \%$ & $4.73 \%$ & $31.51 \%$ & $62.08 \%$ \\
\hline 1997 & $0.49 \%$ & $1.12 \%$ & $4.65 \%$ & $31.33 \%$ & $62.42 \%$ \\
\hline 1998 & $0.48 \%$ & $1.07 \%$ & $4.49 \%$ & $31.05 \%$ & $62.91 \%$ \\
\hline 1999 & $0.49 \%$ & $1.07 \%$ & $4.37 \%$ & $31.44 \%$ & $62.64 \%$ \\
\hline 2000 & $0.50 \%$ & $1.04 \%$ & $4.36 \%$ & $31.51 \%$ & $62.59 \%$ \\
\hline 2001 & $0.50 \%$ & $1.02 \%$ & $4.43 \%$ & $31.67 \%$ & $62.38 \%$ \\
\hline 2002 & $0.49 \%$ & $1.00 \%$ & $4.48 \%$ & $31.92 \%$ & $62.10 \%$ \\
\hline 2003 & $0.49 \%$ & $0.98 \%$ & $4.55 \%$ & $32.26 \%$ & $61.73 \%$ \\
\hline 2004 & $0.48 \%$ & $0.97 \%$ & $4.56 \%$ & $32.43 \%$ & $61.57 \%$ \\
\hline
\end{tabular}

\subsection{Fuel consumption of passenger cars and motorcycles}

Accompanying the growth of motor vehicles, the consumption of fuel increased. By the end of 2004, the energy requirement of the road transportation system reached 14.4 million kiloliters, which was 1.9 times that in 1990 and consumed $22.7 \%$ of the total energy in Taiwan (Figure 1). Despite motorcycles being the primary transport mode for most of the people in Taiwan, the fuel consumption by motorcycles was only $10 \%$ of the road transportation total. As for the variation of motorcycle energy consumption, it was 0.5 million kiloliters in 1990 and 1.9 million kiloliters in 2004, for an increase of $9.89 \%$ per year. Besides, the aggregate fuel demand of passenger cars was estimated to be 3.3 million kiloliters in 1990, accounting for approximately $43.0 \%$ of road transportation's energy consumption. The fuel requirement of passenger cars resulted in 4.1 million kiloliters of energy increase through 1990 to 2004 and continued to rise at an annual growth rate of $5.90 \%$ because of the rapid increase in the 
number of passenger cars. This situation indicates that the high ownership rate and the frequent use of passenger cars and motorcycles will accelerate energy exhaustion, reinforce the seriousness of global warming and deteriorate environmental quality, even though it can facilitate the mobility of people and goods over space and time.

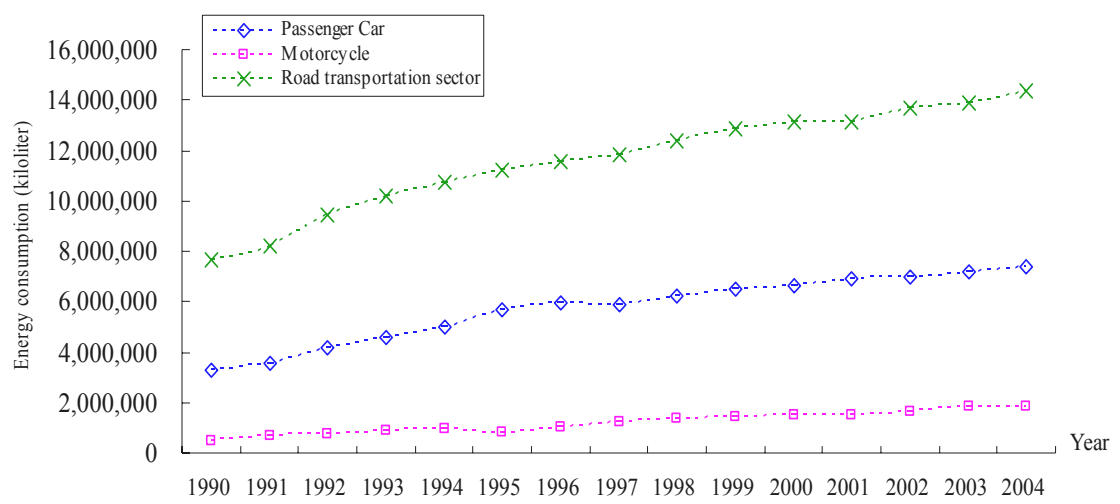

Figure 1: $\quad$ Energy consumption of motor vehicles in Taiwan.

Table 2: $\quad$ Exhaust emission from passenger cars and motorcycles.

\begin{tabular}{|c|c|c|c|c|c|c|}
\hline \multirow{2}{*}{ Year } & \multicolumn{3}{|c|}{ Passenger car } & \multicolumn{3}{c|}{ Motorcycle metric tons } \\
\cline { 2 - 7 } & NOx & CO & HC & NOx & CO & HC \\
\hline 1990 & 99,065 & $1,101,328$ & 259,292 & 17,824 & 153,473 & 127,379 \\
\hline 1991 & 98,122 & $1,053,608$ & 235,986 & 19,373 & 166,723 & 134,076 \\
\hline 1992 & 101,671 & $1,076,887$ & 232,457 & 20,141 & 176,246 & 136,008 \\
\hline 1993 & 97,096 & $1,002,990$ & 207,683 & 20,158 & 180,209 & 134,311 \\
\hline 1994 & 94,979 & 982,191 & 193,760 & 19,402 & 180,993 & 128,848 \\
\hline 1995 & 87,665 & 875,294 & 167,074 & 19,047 & 183,971 & 125,692 \\
\hline 1996 & 79,217 & 774,333 & 144,422 & 18,739 & 188,732 & 124,323 \\
\hline 1997 & 69,733 & 684,917 & 124,020 & 22,793 & 223,380 & 133,866 \\
\hline 1998 & 63,700 & 614,343 & 110,208 & 21,347 & 213,402 & 124,100 \\
\hline 1999 & 60,020 & 555,842 & 100,867 & 20,239 & 226,706 & 120,754 \\
\hline 2000 & 57,982 & 530,181 & 72,365 & 18,682 & 225,324 & 110,442 \\
\hline 2001 & 57,489 & 533,504 & 72,813 & 17,440 & 205,189 & 101,608 \\
\hline 2002 & 76,518 & 969,294 & 120,082 & 18,452 & 219,820 & 106,375 \\
\hline 2003 & 77,262 & $1,010,382$ & 123,752 & 20,587 & 238,448 & 115,734 \\
\hline 2004 & 72,697 & 937,745 & 115,259 & 23,404 & 237,734 & 118,271 \\
\hline
\end{tabular}




\subsection{Pollutant emission of passenger cars and motorcycles}

As mentioned above, road transportation, especially for passenger cars and motorcycles, is responsible for a large share of energy consumption in Taiwan. The transport-related exhaust emissions, such as $\mathrm{NOx}, \mathrm{CO}$ and $\mathrm{HC}$, also play an important role in the development of a sustainable city. The emission data of different pollutants is shown in Table 2. According to the third stage exhaust emission standards, the NOx emission from automobiles should decrease from $0.62 \mathrm{~g} / \mathrm{km}$ in 1990 to $0.25 \mathrm{~g} / \mathrm{km}$. Thus, the NOx emission from passenger cars decreased from 99 thousand tons to 73 thousand tons from 1990 to 2004 , accounting for $24 \%$ of emissions in the road transportation system. During the same period, the NOx emission of motorcycle increased by 6 thousand tons. In addition, the trends of $\mathrm{CO}$ emission changes from passenger cars and motorcycles were similar to those of NOx. The motorcycle $\mathrm{CO}$ emission increased 84 thousand tons, while it declined for passenger cars by 164 thousand tons. The $\mathrm{HC}$ released from passenger cars and motorcycles both decreased. For example, the $\mathrm{HC}$ reduced from $55.6 \%$ for cars and $7.2 \%$ for motorcycles with respect to the HC emissions in 1990.

\subsection{Decomposition of energy consumption in passenger cars and motorcycles}

\subsubsection{Passenger cars}

The fuel consumption of passenger cars has increased 4,069 thousand kiloliters during 1990-2004 (Table 3). The energy intensity was the most important factor for the increase, due to the steady growth of vehicle kilometers of travel and the rapid increase in energy consumption. In total, it contributed 4,286 thousand kiloliters of energy increase. Besides, economic driving force was another indispensable factor that caused increased energy demand. Overall, the fuel consumption for the growth of economy was up to 3,862 thousand kiloliters. Compared to the other increasing factors, the influence of vehicular structure share was much less obvious and the contribution of aggregate energy requirement was 1,472 thousand kiloliters. The index of the vehicle kilometers per unit car had a large positive effect on the reduction of fuel demand in each period, especially for 1990-1993, with a total decrease of 4,638 thousand kiloliters. Furthermore, the aggregate energy conservation based on vehicle expansion was 698 thousand kiloliters because the growth rate of motor vehicles was lower than the increase of economic productivity, which had relatively little effect on energy conservation.

\subsubsection{Motorcycles}

The aggregate change of motorcycle energy consumption increased by 1,374 thousand kiloliters from 1990 to 2004 (Table 3). The steadily increasing trend of economic growth was the most important factor for the increase of vehicular fuel demand. In total, it caused an increase of 858 thousand kiloliters. Because energy intensity contributed 651 thousand kiloliters of energy increase, the measures such as reducing weight, adjusting speed limits, scrapping old 
vehicles and labeling fuel efficiency, etc. should be considered in order to improve vehicular energy efficiency. The relative variation of vehicle kilometers of travel with the number of motorcycles caused an increased energy requirement of 338 thousand kiloliters, which was the result of the higher growth rate in vehicle kilometers of travel. In addition, the major factor for the decrease of fuel demand was vehicle expansion, with an aggregate decrease of 155 thousand kiloliters. Despite the increase in the number of motorcycles by $62.7 \%$ for the past 14 years, the proportion of motorcycles decreased from $68.4 \%$ in 1990 to $61.3 \%$ in 2004 . Thus, the factor of vehicular structure share had a considerable positive contribution to energy conservation and caused a reduction of 125 thousand kiloliters.

Table 3: Decomposition of vehicular energy changes for passenger cars and motorcycles in Taiwan.

unit: thousand kiloliter

\begin{tabular}{|c|c|c|c|c|c|c|c|c|}
\hline \multirow{2}{*}{ Motor Vehicle } & \multirow{2}{*}{ Year } & \multicolumn{7}{|c|}{ Index } \\
\cline { 3 - 8 } & & DI & DK & DS & DV & DG & EC & RD $(\%)$ \\
\hline \multirow{5}{*}{ Passenger car } & $1990-1993$ & 1372.80 & -1709.62 & 0.90 & 782.99 & 841.60 & 1277.35 & $-0.89 \%$ \\
\cline { 2 - 9 } & $1993-1996$ & 1444.77 & -1122.49 & 1294.86 & -1275.43 & 996.90 & 1331.41 & $-0.54 \%$ \\
\cline { 2 - 9 } & $1996-1999$ & 425.91 & -344.56 & -14.74 & -473.44 & 1009.97 & 602.67 & $-0.08 \%$ \\
\cline { 2 - 9 } & $1999-2002$ & 350.16 & -564.70 & 103.71 & 103.54 & 475.78 & 468.29 & $-0.04 \%$ \\
\cline { 2 - 9 } & $2002-2004$ & 423.53 & -589.80 & 112.96 & -181.61 & 624.59 & 389.58 & $-0.02 \%$ \\
\cline { 2 - 9 } & $1990-2004$ & 4286.31 & -4637.87 & 1472.06 & -697.71 & 3862.32 & 4069.29 & $-5.30 \%$ \\
\hline \multirow{5}{*}{ Motorcycle } & $1990-1993$ & 258.26 & -170.21 & 10.38 & 136.05 & 146.23 & 371.22 & $-2.55 \%$ \\
\cline { 2 - 9 } & $1993-1996$ & -42.13 & 320.04 & -104.46 & -226.68 & 177.18 & 123.77 & $-0.15 \%$ \\
\cline { 2 - 9 } & $1996-1999$ & 115.59 & 206.35 & 10.82 & -92.24 & 196.77 & 432.60 & $-1.08 \%$ \\
\cline { 2 - 9 } & $1999-2002$ & 106.57 & -6.65 & -13.23 & 23.56 & 108.27 & 218.15 & $-0.17 \%$ \\
\cline { 2 - 8 } & $2002-2004$ & 92.50 & 42.54 & -15.27 & -44.50 & 153.04 & 227.99 & $-0.14 \%$ \\
\cline { 2 - 8 } & $1990-2004$ & 651.40 & 338.18 & -124.81 & -155.01 & 858.11 & 1373.73 & $-14.13 \%$ \\
\hline
\end{tabular}

* DE: energy intensity, DK: vehicle kilometers per unit vehicle, DS: vehicular structure share, DV: vehicle intensity, DG: economic productivity, EC: emission changes, RD: residuals.

\section{Conclusion}

Results of this study indicate that the high economic growth and the frequent use of private vehicles are the major factors for the greater transport volumes among vehicles. Accompanying the growth of motor vehicles, the consumption of vehicle fuels for passenger cars and motorcycles increased at the annual growth rate of $5.90 \%$ and $9.89 \%$ from 1990 to 2004 . The transport-related exhausted emission from automobile had a steady tendency toward decline, while the performances of motorcycle's NOx and CO emissions suggest that the retirement of high-aged vehicles and the implementation of green transport modes should be enhanced. Furthermore, the analysis of decomposition methodology reveal that Taiwan's economic growth and energy intensity are two key factors for the rise of vehicular fuel consumption, while vehicle intensity had a significant effect on energy conservation. The factor of vehicle kilometers per unit car had a 
negative effect on motorcycle energy requirements but it contributed 4,638 thousand kiloliters of energy conservation by passenger cars. The increase of passenger car share caused an increase in energy demand of 1,472 thousand kiloliters. Compared with the increased effect to passenger car's fuel demand, the reduction of energy consumption reached 125 thousand kiloliters because the share of motorcycles decreased from $68.4 \%$ to $61.3 \%$.

Because of high population density, the limitations of topography and natural resources and the shortage of a well-established public transport system, the ownership of private vehicles, especially for motorcycles, is higher than that in most other countries. To reduce the requirements of energy consumption and the ownership of private vehicles, the strategies include (1) proper fuel/car taxation; (2) a well-developed feeder system by MRT and integrated road-rail networks;

(3) enhancing high occupancy vehicle measures and bus lanes by regulatory and economic incentives; and (4) adjusting speed limits and strengthening energy conservation standards for new vehicles.

\section{References}

[1] Bureau of Energy, Ministry of Economic Affairs, Republic of China, 2006. Energy balances in Taiwan Republic of China 2005.

[2] Ministry of Transportation and Communications. Statistical Abstract of Transportation and Communications, 2006.

[3] Ang, B. W. and Lee, S. Y., Decomposition of industrial energy consumption: some methodological and application issues. Energy Economics, 16 (2), pp. 83-92, 1994.

[4] Lin, Sue J. and Chang, Tzu C., Decomposition of $\mathrm{SO}_{2}, \mathrm{NO}_{\mathrm{x}}$ and $\mathrm{CO}_{2}$ emissions from energy use of major economic sectors in Taiwan. The Energy Journal, 17, pp. 1-17, 1996.

[5] Ang, B.W. and Pandiyan G., Decomposition of energy-induced $\mathrm{CO}_{2}$ emissions in manufacturing. Energy Economics, 19, pp. 363-374, 1997.

[6] Mazzarino, Marco, The economics of the greenhouse effect: evaluating the climate change impact due to the transport sector in Italy. Energy Policy, 28, pp. 957-966, 2000.

[7] Lee, Cheng F. and Lin, Sue J., Structural decomposition of $\mathrm{CO}_{2}$ emissions from Taiwan's petrochemical industries. Energy Policy, 29, pp. 237-244, 2001.

[8] Ang, B.W., Decomposition analysis for policymaking in energy: which is the preferred method?. Energy Policy, 32, pp. 1131-1139, 2004.

[9] Paula, Shyamal and Bhattacharya Rabindra Nath., $\mathrm{CO}_{2}$ emission from energy use in India: a decomposition analysis. Energy Policy, 32, pp. 585593, 2004.

[10] Ang, B.W., The LMDI approach to decomposition analysis: a practical guide. Energy Policy, 33, pp. 867-871, 2005.

[11] Lin, Sue J., Lu, I. J. and Lewis, C., Identifying key factors and strategies for reducing industrial $\mathrm{CO}_{2}$ emissions from a non-Kyoto protocol member's (Taiwan) perspective. Energy Policy, 34, pp. 1499-1507, 2006. 